\title{
Static respiratory compliance in the newborn. I: A clinical and prognostic index for mechanically ventilated infants
}

\author{
William O Tarnow-Mordi, Rosalie A Wilkie, Elizabeth Reid
}

\begin{abstract}
Accurate measures of the severity of respiratory disease are important, both clinically and epidemiologically. The apparent prognostic value of static respiratory system compliance (Crs) on the first day and mean appropriate fractional inspired oxygen $\left(\mathrm{FIO}_{2}\right)$ in the first 12 hours of life were compared in 48 infants who received mechanical ventilation in $a$ regional neonatal unit. Their median (range) gestation was $30(25-41)$ weeks and they were representative of all 140 newborn infants born to residents of a geographically defined area who received mechanical ventilation over a 30 month period. Using the best cut off value $(\leqslant 0.6$ $\mathrm{m} 1 / \mathrm{cm} \mathrm{H}_{2} \mathrm{O} / \mathrm{m}$ corrected for body length), static Crs predicted hospital death with $98 \%$ accuracy, $80 \%$ sensitivity, and $100 \%$ specificity. Using the best cut off value $(>0 \cdot 60)$, mean $\mathrm{FIO}_{2}$ in the first 12 hours predicted hospital death with $81 \%$ accuracy, $80 \%$ sensitivity, and $81 \%$ specificity. Static Crs appeared to be a more accurate measure of respiratory function and disease severity than mean $\mathrm{FIO}_{2}$, perhaps because static Crs is less dependent on ventilator management than routine indices based on blood gases. Static Crs now merits wider evaluation, both as an aid to routine clinical management and as a prognostic index in comparative studies. (Arch Dis Child 1994; 70: F11-F15)
\end{abstract}

Accurate assessment of disease severity is fundamental both for clinical management and in epidemiological studies. Clinically, any mismatch between the intensity of mechanical ventilation and the severity of respiratory disease - whether through over or under treatment - can have serious consequences. Individual assessment of respiratory disease severity demands considerable skill to interpret the degree of chest wall movement, the chest radiograph, and blood gas measurements. Unfortunately, blood gases can be misleading when impaired gas exchange is due to inappropriate ventilator settings leading to inadvertent positive end expiratory pressure ${ }^{1}$ or obstruction of the pulmonary circulation.

\section{Case reports}

PATIENT A

A boy was delivered by caesarean section because of breech presentation in established labour at 28 weeks' gestation. Ultrasonography from 22 weeks' gestation had suggested oligohydramnios. At birth he was resuscitated by endotracheal intubation with intermittent positive pressure ventilation and admitted to the neonatal unit where he received elective mechanical ventilation. The ventilator pressures and inspiratory: expiratory ratio were progressively increased (table 1). At 6 hours of age he was moribund, with extremely poor peripheral perfusion, a mean aortic blood pressure below $20 \mathrm{~mm} \mathrm{Hg}$, severe hypoxia, and respiratory acidosis. His chest wall expanded well with each ventilator inflation and his chest radiograph showed clear lung fields with overexpansion and no evidence of pulmonary hypoplasia. Severe pulmonary and peripheral underperfusion due to compression of the pulmonary vessels, heart, and aorta were diagnosed. The ventilator peak pressure and inspiratory:expiratory ratio were decreased and the ventilator rate was temporarily increased to reduce the arterial carbon dioxide tension $\left(\mathrm{PaCO}_{2}\right)$. His arterial blood gases and blood pressure rapidly returned to normal. He continued to breathe air and was extubated successfully on the fifth day.

\section{PATIENT B}

A boy was delivered by emergency caesarean section after placental abruption in labour at

Table 1 Effects of inappropriate ventilator settings on gas exchange

Patient $A^{\star}$

Age (hours)

Inspiratory time (sec)

Expiratory time (sec)

Inspiratory:expiratory ratio

Peak inspiratory pressure $\left(\mathrm{cm} \mathrm{H}_{2} \mathrm{O}\right)$

End expiratory pressure $\left(\mathrm{cm} \mathrm{H}_{2} \mathrm{O}\right)$

Mean airway pressure $\left(\mathrm{cm} \mathrm{H}_{2} \mathrm{O}\right)$

$\mathrm{FaO}_{2}(\mathrm{kPa})$

$\mathrm{PaCO}_{2}(\mathrm{kPa})$

Patient B十

Age (hours)

Inspiratory time (sec)

Expiratory time (sec)

Inspiratory:expiratory ratio

Peak inspiratory pressure $\left(\mathrm{cm} \mathrm{H}_{2} \mathrm{O}\right)$

End expiratory pressure ( $\left.\mathrm{cm} \mathrm{H}_{2} \mathrm{O}\right)$

Mean airway pressure $\left(\mathrm{cm} \mathrm{H}_{2} \mathrm{O}\right)$

$\mathrm{FIO}_{2}$

$\mathrm{PaO}_{2}(\mathrm{kPa})$

$\mathrm{PaCO}_{2}(\mathrm{kPa})$

$\mathrm{pH}$

$\begin{array}{ccc}0 \cdot 5 & 6 & 9 \\ 0 \cdot 5 & 0 \cdot 8 & 0 \cdot 25 \\ 1 \cdot 0 & 0 \cdot 2 & 0 \cdot 25 \\ 1: 2 & 4: 1 & 1: 1 \\ 20 & 32 & 18 \\ 2 & 2 & 3 \\ 6 \cdot 3 & 24 \cdot 5 & 9 \cdot 0 \\ 0 \cdot 4 & 1 \cdot 0 & 0 \cdot 4 \\ 3 \cdot 6 & 1 \cdot 5 & 9 \cdot 2 \\ 9 \cdot 1 & 10 \cdot 5 & 5 \cdot 3 \\ 7 \cdot 16 & 7 \cdot 08 & 7 \cdot 27 \\ & & \\ 2 & 5 \cdot 5 & 7 \\ 0 \cdot 75 & 0 \cdot 6 & 0 \cdot 6 \\ 0 \cdot 45 & 0 \cdot 4 & 1 \cdot 4 \\ 1 \cdot 7: 1 & 1 \cdot 5: 1 & 1: 2 \cdot 3 \\ 23 & 23 & 19 \\ 5 & 4 & 4 \\ 13 \cdot 4 & 16 \cdot 0 & 8 \cdot 0 \\ 0 \cdot 45 & 0 \cdot 3 & 0 \cdot 21 \\ 8 \cdot 5 & 10 \cdot 1 & 11 \cdot 5 \\ 7 \cdot 2 & 5 \cdot 7 & 4 \cdot 1 \\ 7 \cdot 28 & 7 \cdot 35 & 7 \cdot 47 \\ & & \end{array}$

*Patient A: dramatic illustration of the effect of inappropriately high ventilator pressure and inspiratory: expiratory ratio settings. The resulting compression of the pulmonary circulation, probably accompanied by inadvertent PEEP caused severe hypoxia and respiratory acidosis, which resolved when the settings were reduced.

tPatient B: less dramatic example of a similar problem. (See case reports.) 
29 weeks' gestation. He was intubated at birth and received elective mechanical ventilation on admission to the neonatal unit. His chest radiograph at 3 hours of age showed diffuse reticulogranular densities and prominent hilar vessels, with no air bronchograms and no loss of the cardiac outline. He initially required a fractional inspired oxygen $\left(\mathrm{FIO}_{2}\right)$ of 0.4 (table 1). Measurement of respiratory function by a computerised passive expiratory flow technique $^{2}$ showed that respiratory compliance was relatively good $\left(1.8 \mathrm{ml} / \mathrm{cm} \mathrm{H}_{2} \mathrm{O} / \mathrm{m}\right)$ and the expiratory time constant was 0.19 seconds. This indicated that the lungs needed 0.57 seconds (that is three time constants) to achieve $95 \%$ emptying in passive expiration, that is, that the ventilator expiratory time was probably too short and the infant receiving inadvertent positive end expiratory pressure. The ventilator peak pressure and inspiratory:expiratory ratio were reduced and the ventilator expiratory time increased. The infant was successfully extubated at 12 hours of age, breathing air.

Epidemiologically, there has been longstanding interest in developing reliable methods to compare the outcome of respiratory care between different neonatal units. In particular, a seminal study by Avery et al has stimulated valuable insights and questions. ${ }^{3}$ This and similar studies remain difficult to interpret, however, because they lack measures of disease severity, without which there is no guarantee that like was compared with like. The best way to achieve comparability is by randomised studies, which tend to balance all prognostic variables (including disease severity) equally between groups. However, to compare the performance of neonatal units in this way would mean randomly transferring babies to receive intensive care in any of the neonatal units under study, which is not feasible. Comparisons of this kind must therefore use observational methods. These would be more reliable if accurate measures of initial disease severity were routinely recorded so that adjustments could be made for differences in casemix between the denominator (that is, treated) populations.

Provided oxygenation is adequately monitored, indices of oxygen requirement over the first 12 hours of life such as the mean or minimum and maximum appropriate $\mathrm{FIO}_{2}$ or the mean arterial/alveolar oxygen ratio may provide routine measures of the initial severity of respiratory disease. In very low birthweight infants such indices seem at least as strongly associated with subsequent mortality as are traditional variables like birth weight, gestation, or hyaline membrane disease. ${ }^{45}$ Static respiratory system compliance (Crs) measured in the first 8 hours of life has also been strongly associated with subsequent mortality in mechanically ventilated infants. ${ }^{6}$ We therefore compared the potential clinical and epidemiological value of static Crs in the first day of life with mean $\mathrm{FIO}_{2}$ in the first 12 hours of life in a representative group of infants receiving mechanical ventilation in a regional neonatal unit.

\section{Patients and methods}

The study was conducted between April 1988 and September 1990 among infants admitted to the neonatal unit at Ninewells Hospital and Medical School. Infants were included if they had been born to residents of Tayside and were receiving mechanical ventilation by endotracheal tube, did not have an intercostal chest drain, and if one of the authors (RAW or WOT-M) was available to measure static Crs on the first day of life.

Static Crs was measured with infants supine employing a computerised passive expiratory flow technique. ${ }^{2}$ This used a two way valve with a dead space of $4 \mathrm{ml}$ to occlude airway flow and trap gas in the chest at or near maximum inflation for $0.2-0.5$ seconds, which usually induced a Hering-Breuer reflux with relaxation of the respiratory muscles. The subsequent passive expiration was diverted via the other limb of the two way valve through a Fleisch 0 pneumotachograph (linear between 0 and $300 \mathrm{ml}$ per sec) connected to a pressure transducer (Validyne MP $45 \pm 2 \quad \mathrm{~cm} \mathrm{H}_{2} \mathrm{O}$ ), which was sited outside the ventilator circuit and thus did not add to the dead space of the apparatus. The two way valve was cleaned thoroughly with alcohol between patients. The flow-volume characteristics of this expiratory breath were analysed using a system developed at the Children's Hospital, Toronto, by Professor A C Bryan, Dr M H Bryan, and Dr P N Le Souef.

Airway pressure was measured using a Validyne or Furness Controls transducer $(0-10 \mathrm{kPa})$; flow and pressure signals were recorded from the pneumotachograph by an on line computer (IBM PC) at a sampling rate of $250 \mathrm{~Hz}$ per channel. The flow was digitally integrated and the resultant expiratory flowvolume curve displayed on the computer monitor. Flow-volume curves were only selected for analysis if the preceding airway pressure trace showed a flat plateau, indicating that no leak was occurring around the endotracheal tube. Respiratory function data were used only if the linear portion of the flowvolume curve accounted for two thirds or more of the expiration and the correlation coefficient of its slope exceeded 0.996 .

In each study an average static Crs was obtained from flow-volume studies from between four and 12 passive expirations. Each measurement was preceded by endotracheal suction to avoid variations in airway resistance caused by secretions. Elsewhere we have reported that the mean (SD) within-study coefficient of variation in Crs between accepted breaths is $6 \cdot 7(3.5) \%$, the mean (SD) difference between the results of paired studies performed five minutes apart by the same observer is $0.2(10.5) \%$ and the mean (SD) difference between results obtained by two mutually blinded observers analysing the same data is $0.4(7.4) \% .^{7}$ The apparatus was calibrated weekly, because of the lack of drift on 
Table 2 Characteristics of mechanically ventilated infants born to residents of Tayside in study period (data are expressed as median (range) except for hospital death and $\mathrm{FIO}_{2}$ )

\begin{tabular}{|c|c|c|}
\hline & $\begin{array}{l}\text { Static Crs measured on } \\
\text { first day of life } \\
(n=48)\end{array}$ & $\begin{array}{l}\text { Static Crs not } \\
\text { measured } \\
(n=92)\end{array}$ \\
\hline $\begin{array}{l}\text { No of hospital deaths } \\
\text { Birth weight (g) } \\
\text { Gestation (weeks) } \\
\text { Length (cm) } \\
\text { Age when Crs first measured (hours) } \\
\text { Uncorrected Crs (ml/cm } \mathrm{H}_{2} \mathrm{O} \text { ) } \\
\text { Crs corrected for body length }\left(\mathrm{ml} / \mathrm{cm} \mathrm{H}_{2} \mathrm{O} \text { ) }\right. \\
\mathrm{Mean} \mathrm{FIO}_{2} \text { in first } 12 \text { hours }\end{array}$ & $\begin{array}{l}5 \\
1270(480-3500) \\
30(25-41) \\
39(30-51) \\
5 \cdot 5(0-24) \\
0 \cdot 55(0 \cdot 2-2 \cdot 0) \\
1 \cdot 4(0 \cdot 6-4 \cdot 2) \\
0 \cdot 41(0 \cdot 21-0 \cdot 79)\end{array}$ & $\begin{array}{l}11 \\
1440(460-4100) \\
30(24-39)\end{array}$ \\
\hline
\end{tabular}

There were no significant differences between the two groups in hospital mortality, birth weight, gestation, or mean $\mathrm{FIO}_{2}$ in first 12 hours.

day to day calibration. The pneumotachograph was calibrated using $100 \%$ oxygen. No attempt was made to correct for variations in gas composition. A single measurement of crown-heel length to within $\pm 1.5 \mathrm{~cm}$ was made at the time of the first Crs measurement using a tape measure.

$\mathrm{FIO}_{2}$ was strictly controlled by continuously maintaining appropriate oxygenation, defined as arterial haemoglobin oxygen saturation between $90-94 \%$ using pulse oximeters (Nellcor) or transcutaneous oxygen tension between 6.7-10.5 kPA using transcutaneous oxygen electrodes (Simonsen and Weil). Mean $\mathrm{FIO}_{2}$ was calculated as the average of all appropriate $\mathrm{FIO}_{2}$ recordings on blood gas flow charts in the first 12 hours of life.

Table 3 Classification matrices for prognostic indices in relation to hospital death using best cut off points for each variable

\begin{tabular}{|c|c|c|c|c|}
\hline & \multicolumn{2}{|c|}{ Predicted } & \multirow[b]{2}{*}{ Total } & \multirow[b]{2}{*}{ Significance } \\
\hline & Alive & Dead & & \\
\hline \multirow{2}{*}{$\begin{array}{l}\text { Crs corrected for length }\left(\mathrm{mL} / \mathrm{cm} \mathrm{H}_{2} \mathrm{O} / \mathrm{m}\right) \\
\text { Observed: } \\
\text { Lived } \\
\text { Died }\end{array}$} & $>0.6$ & $\leqslant 0.6$ & & \\
\hline & $\begin{array}{r}43 \\
1\end{array}$ & $\begin{array}{l}0 \\
4\end{array}$ & $\begin{array}{r}43 \\
5\end{array}$ & \\
\hline Total & 44 & 4 & 48 & $\chi^{2}=27 \cdot 8 ; p=0 \cdot 00000014$ \\
\hline \multirow{2}{*}{$\begin{array}{l}\text { Gestation (weeks) } \\
\text { Observed: } \\
\text { Lived } \\
\text { Died }\end{array}$} & $\geqslant 29$ & $<28$ & & \\
\hline & $\begin{array}{r}37 \\
0\end{array}$ & $\begin{array}{l}6 \\
5\end{array}$ & $\begin{array}{r}43 \\
5\end{array}$ & \\
\hline Total & 37 & 11 & 48 & $\chi^{2}=14 \cdot 2 ; p=0.00016$ \\
\hline \multirow{2}{*}{$\begin{array}{l}\text { Crs corrected for birth weight }\left(\mathrm{ml} / \mathrm{cm} \mathrm{H}_{2} \mathrm{O} / \mathrm{kg}\right) \\
\text { Observed: } \\
\text { Lived } \\
\text { Died }\end{array}$} & $>0.3$ & $\leqslant 0 \cdot 3$ & & \\
\hline & $\begin{array}{r}36 \\
1\end{array}$ & $\begin{array}{l}7 \\
4\end{array}$ & $\begin{array}{r}43 \\
5\end{array}$ & \\
\hline Total & 37 & 11 & 48 & $\chi^{2}=7 \cdot 0 ; p=0.008$ \\
\hline Mean $\mathrm{FIO}_{2}$ in first 12 hours & $\leqslant 0.6$ & $>0.6$ & & \\
\hline $\begin{array}{l}\text { Observed: } \\
\text { Lived } \\
\text { Died }\end{array}$ & $\begin{array}{r}35 \\
1\end{array}$ & $\begin{array}{l}8 \\
4\end{array}$ & $\begin{array}{r}43 \\
5\end{array}$ & \\
\hline Total & 36 & 12 & 48 & $\chi^{2}=6 \cdot 0 ; p=0.014$ \\
\hline $\begin{array}{l}\text { Hyaline membrane disease (HMD) } \\
\text { Observed: } \\
\text { Lived } \\
\text { Died }\end{array}$ & $\begin{array}{c}\text { No } H N \\
21 \\
0\end{array}$ & $\begin{array}{l}\text { ID } H M D \\
22 \\
5\end{array}$ & $\begin{array}{r}43 \\
5\end{array}$ & \\
\hline Total & 21 & 27 & 48 & $\chi^{2}=2 \cdot 58 ; p=0 \cdot 10$ \\
\hline
\end{tabular}

Distributions and classification matrices for birth weight, uncorrected Crs and Crs corrected for gestation were identical to those for Crs corrected for length, with cut off points for bes discrimination for death of $\leqslant 750 \mathrm{~g}, \leqslant 0 \cdot 2 \mathrm{ml} / \mathrm{cm} \mathrm{H}_{2} \mathrm{O}$, and $<0.01 \mathrm{ml} / \mathrm{cm} \mathrm{H}_{2} \mathrm{O} /$ week.

Table $4 \%$ Predictive power of variables

\begin{tabular}{llrrrr}
\hline & Accuracy & Sensitivity & Specificity & \multicolumn{1}{l}{$\begin{array}{l}\text { Positive } \\
\text { predictive } \\
\text { value }\end{array}$} & $\begin{array}{l}\text { Negative } \\
\text { predictive } \\
\text { value }\end{array}$ \\
\hline Crs corrected for length & $98(47 / 48)$ & $80(4 / 5)$ & $100(43 / 43)$ & $100(4 / 4)$ & $98(43 / 44)$ \\
Gestation & $88(42 / 48)$ & $100(5 / 5)$ & $86(37 / 43)$ & $45(5 / 11)$ & $100(37 / 37)$ \\
Crs corrected for birth weight & $83(40 / 48)$ & $80(4 / 5)$ & $84(36 / 43)$ & $36(4 / 11)$ & $97(36 / 37)$ \\
Mean Fio 2 in first 12 hours & $81(39 / 48)$ & $80(4 / 5)$ & $81(35 / 43)$ & $33(4 / 12)$ & $97(35 / 36)$
\end{tabular}

No predictive power is reported for hyaline membrane disease because the distributions of deaths and survivors were not statistically significantly different.
All infants were treated with Sechrist IV $100 \mathrm{~B}$ ventilators (Anaheim, CA). Respiratory distress syndrome was diagnosed if an infant had a chest radiograph between 4-8 hours of age showing reticulogranular densities or a 'ground glass' appearance, or diffuse opacification with air bronchograms. No infant received exogenous surfactant. The study was approved by the Tayside committee on medical ethics.

\section{STATISTICAL ANALYSIS}

Group medians of non-normally distributed data were compared by Mann-Whitney U test and means of normally distributed data by Student's $t$ test. Associations between hospital death and mean $\mathrm{FIO}_{2}$, Crs, birth weight, gestation, and hyaline membrane disease were tested on univariate analyses by $\chi^{2}$ test with Yates's correction, selecting cut off values for each variable which yielded the best discrimination between survival and death. The proportions of deaths and survivors thus classified by each variable were calculated and compared using the following definitions: true positives $=\mathrm{TP}$, true negatives $=\mathrm{TN}$, false positives $=\mathrm{FP}$, false negatives $=\mathrm{FN}$; accuracy $=(\mathrm{TP}+\mathrm{TN}) /$ total, sensitivity $=\mathrm{TP} / \mathrm{TP}+$ $\mathrm{FN})$, specificity $=\mathrm{TN} /(\mathrm{TN}+\mathrm{FP})$, positive predictive value $=\mathrm{TP} /(\mathrm{TP}+\mathrm{FP})$, and negative predictive value $=\mathrm{TN} /(\mathrm{TN}+\mathrm{FN})$.

\section{Results}

Characteristics of all 140 mechanically ventilated infants born to residents of Tayside during the study period are shown in table 2 . The 48 infants studied did not differ in important prognostic characteristics from the 92 who were not, suggesting that the study group was a representative sample. Measurements of static Crs took up to 10-15 minutes and were well tolerated by the infant, with no evidence of destabilisation of oxygenation or - when it was continuously monitored carbon dioxide tension. Of these 48 infants, 15 had no radiographic evidence of respiratory distress syndrome in the first 8 hours, and included babies ventilated electively or for asphyxia or congenital heart disease, with mean (SD) static Crs $1.9(0.8) \mathrm{ml} / \mathrm{cm} \mathrm{H}_{2} \mathrm{O} / \mathrm{m}$; five had transient tachypnoea of the newborn with mean (SD) static Crs $1.6(0.5) \mathrm{ml} / \mathrm{cm}$ $\mathrm{H}_{2} \mathrm{O} / \mathrm{m}$, one had pneumonia with static $\mathrm{Crs}$ $1.2 \mathrm{ml} / \mathrm{cm} \mathrm{H}_{2} \mathrm{O} / \mathrm{m}$, and 27 had respiratory distress syndrome with static Crs $1.3(0.5) \mathrm{ml} / \mathrm{cm}$ $\mathrm{H}_{2} \mathrm{O} / \mathrm{m}$, which accounted for all five deaths. Tables 3 and 4 show classification matrices and the apparent predictive power of each variable using those cut off values that best discriminated between survival and death in Ninewells Hospital.

\section{Discussion}

This preliminary study shows that mean $\mathrm{FIO}_{2}$ in the first 12 hours and static Crs measured on the first day were closely associated with subsequent mortality in mechanically ventilated 
newborn infants, corroborating previous evidence of their apparent prognostic value. ${ }^{4-6}$ While both indices had considerable apparent predictive power, static $\mathrm{Crs}$ was the more accurate. These findings appear to be at variance with those of a recent investigation that used the same technique for measuring static $\mathrm{Crs} .^{8}$ However, in that report the population may have been unrepresentative because of a selection bias towards low risk infants, reflected in an unusually low mortality. As only 18 infants were mechanically ventilated in the study of Simbruner et $a l,{ }^{6}$ to our knowledge ours is the largest yet reported of early static Crs in relation to mortality in a representative sample of newborn infants receiving mechanical ventilation. It was still relatively small, however, so some of the findings should be interpreted with caution.

Firstly, cut off values for each prognostic variable to distinguish between death and survival were not specified in advance, which increases the risk of a type 1 error. Although we could have prespecified $\leqslant 0.5 \mathrm{ml} / \mathrm{cm} \mathrm{H}_{2} \mathrm{O}$ as a cut off value for uncorrected static $\mathrm{Crs}$ because it best discriminated between death and survival in the study of Simbruner et $a l,^{6}$ we decided against it because that work was conducted a decade earlier. Indeed, the fact that a lower value of uncorrected static $\mathrm{Crs}$ of $\leqslant 0.2 \mathrm{ml} / \mathrm{cm} \mathrm{H} \mathrm{H}_{2} \mathrm{O}$ best discriminated between death and survival in our study is consistent with the fact that the prognosis for mechanically ventilated infants had improved. The best cut off point for predicting mortality may now be even lower, after the introduction of multiple dose surfactant treatment. It is important to stress that the likelihood that low static Crs and death are associated by chance alone in both studies is vanishingly small.

Secondly, static Crs was obtained over a longer period after birth than mean $\mathrm{FIO}_{2}$. This may have biased the comparison of predictive power in favour of static Crs as - as in a horse race - predictions tend to be more successful the later they are made. Thirdly, both gestation and birth weight were closely related to death (table 3), so they may have confounded the associations between static $\mathrm{Crs}$, mean $\mathrm{FIO}_{2}$, and death. We have not attempted to analyse these associations independently by multiple regression because of the small sample size. However, we found previously that mean $\mathrm{FIO}_{2}$ in the first 12 hours was an independent and more important predictor of death than gestation or birth weight. ${ }^{4}$ Furthermore, Simbruner et al found that in infants with respiratory symptoms static Crs was not correlated with gestation at all. ${ }^{6}$

It is important to correct measurements of Crs for body size. Otherwise in small infants an apparent association between low, uncorrected Crs and death might reflect the small size of the lungs rather than disease severity. Crs has been corrected for functional residual capacity (FRC), weight, length, and length cubed but none is ideal. In healthy subjects Crs is often expressed as specific lung compliance by correcting for FRC, but FRC cannot always be measured and may itself be reduced in surfac- tant deficiency. Should static Crs be corrected for weight or for length? Weight may fluctuate substantially in the first weeks of life, while length is hard to measure accurately in babies. Neonatologists have tended to correct Crs measurements for birth weight, while paediatricians, respiratory physicians, and physiologists have used length (or height). Studies in normal infants suggest that static Crs is linearly related with weight but that its relationship with length is curvilinear. ${ }^{9-12}$ Neither line passes through the origin: static Crs plotted against weight intercepts the Crs axis while static Crs plotted against length intercepts the length axis. ${ }^{1012}$ Thus correction for length could slightly overestimate the disease severity of smaller infants and underestimate the disease severity of larger infants. Correction for weight could have the opposite effect, perhaps predisposing larger infants with less severe lung disease to be treated with surfactant unnecessarily. ${ }^{7}$ As length was estimated to within $\pm 1.5 \mathrm{~cm}$, errors in its measurement in a baby $40 \mathrm{~cm}$ long with static Crs of $1.0 \mathrm{ml} / \mathrm{cm}$ $\mathrm{H}_{2} \mathrm{O}$ could lead to variations of $\pm 0.1 \mathrm{~cm}$ $\mathrm{H}_{2} \mathrm{O} / \mathrm{m}$. Despite this, correction of static Crs for length has proved a marginally better discriminator of death (tables 3 and 4) and lung immaturity ${ }^{13}$ than static Crs corrected for birthweight. We were unable to determine a normal range for static Crs as few babies with normal lungs were intubated. In healthy preterm babies the normal range for static Crs is approximately $0.8-4.0 \mathrm{ml} / \mathrm{cm} \quad \mathrm{H}_{2} \mathrm{O}$ or $0.5-1.7 \mathrm{ml} / \mathrm{cm} \mathrm{H} \mathrm{H}_{2} \mathrm{O} / \mathrm{kg} .{ }^{9}{ }^{10}$ However, these data were obtained using a facemask and may not be completely comparable with data in intubated babies. More data on static Crs values in normal and diseased infants of all ages and sizes are needed.

Our findings have clear clinical implications. Firstly, while blood gas measurements are an important clinical index of disease severity, they can be misleading if, for example, the infant is overtreated with inappropriate ventilator settings, ${ }^{1}$ as illustrated in the case reports. The problem of overtreatment could become more common as antenatal and postnatal steroids ${ }^{1415}$ and exogenous surfactant treatment reduce the severity and duration of respiratory disease. Is static Crs a better clinical index than dynamic compliance? If excessive peak inflation pressure is used both static and dynamic compliance may be underestimated because the lungs are operating on a flatter portion of the pressure volume curve. In other circumstances, however, static Crs may be less liable to distortion by ventilator management. ${ }^{16}$ For dynamic compliance, tidal volume is constrained by the ventilator settings between the peak and positive end expiratory pressures (PEEP). The lung may thus remain overdistended during expiration because of continuing PEEP, leading to reduced tidal volume and underestimation of true lung compliance. In contrast, during measurement of static Crs in passive expiration the lung deflates to atmospheric pressure and tends to return to its natural functional residual capacity. Static Crs may thus provide a robust, 
Table 5 Performance of various prognostic indices in predicting death in hospital

\begin{tabular}{|c|c|c|c|}
\hline & No & $\begin{array}{l}\text { Sensitivity } \\
(\%)\end{array}$ & $\begin{array}{l}\text { Specificity } \\
(\%)\end{array}$ \\
\hline $\begin{array}{l}\text { Neonatal Crs } \leqslant 0.5 \mathrm{ml} / \mathrm{cm} \mathrm{H}_{2} \mathrm{O} \text { (Vienna Children's Hospital) }^{6 \star} \\
\text { VLBW infant predictive model }{ }^{4} \dagger \\
\text { Neonatal Crs } \leqslant 0.6 \mathrm{mV} / \mathrm{cm} \mathrm{H}_{2} \mathrm{O} / \mathrm{m} \ddagger \text { (Ninewells Hospital) }^{\star} \\
\text { Physiology stability index } \\
\text { NIH VLBW infant model }{ }^{23} \\
\text { APACHE II }\end{array}$ & $\begin{array}{r}82 \\
262 \\
48 \\
2400 \\
387 \\
5030\end{array}$ & $\begin{array}{l}89 \\
81 \\
80 \\
67 \\
54 \\
47\end{array}$ & $\begin{array}{r}99 \\
75 \\
100 \\
99 \\
89 \\
95\end{array}$ \\
\hline
\end{tabular}

$\mathrm{VLBW}=$ very low birthweight.

^Except for those based on neonatal Crs, each index was generated in a 'training sample' of patients and validated in a separate 'test sample' of patients; 18 of the 82 patients in Vienna were mechanically ventilated. 6

IIn this study the 'training' and 'test' samples excluded infants who were admitted to the intensive care units but did not receive assisted ventilation. Because their risk of death is low, had such infants been included the specificity of the model would have increased, with little change in its sensitivity.

$\ddagger$ Equivalent to Crs $\leqslant 0 \cdot 2 \mathrm{ml} / \mathrm{cm} \mathrm{H}_{2} \mathrm{O}$ uncorrected for body length.

independent measure of respiratory function ${ }^{13}$ and disease severity to supplement blood gas measurements and perhaps improve clinical management (patient B).

Secondly, early and accurate prognostic indices could enhance clinical audit by focusing attention on the management of infants who die (or survive) unexpectedly. They could also provide clinical staff and parents with clearer prognoses soon after admission. However, it would be unwise to withdraw intensive care in any individual simply because the calculated risk of death is high, as the calculations are derived from previous cohorts of infants. Prognosis in neonatal intensive care is changing rapidly and healthy survival against the odds is always possible.

Our findings may also have implications for perinatal epidemiology and health service research. Predictive models or scoring systems based on early severity of disease are being developed in several disciplines ${ }^{17-20}$ to allow better prognostication and more reliable comparisons of clinical outcome adjusted for casemix. Table 5 compares the predictive power of some of these systems with that of static Crs and early oxygenation in this study and suggests that such prognostic systems may be robust and widely applicable.

Reliable routine indices of initial disease severity could also improve the interpretation of many comparative studies. The randomised controlled trial of high frequency oscillatory ventilation versus conventional ventilation reported by the HIFI group showed no overall difference in chronic lung disease between the two groups. ${ }^{21}$ Nevertheless it is still possible that high frequency oscillation prevents chronic lung disease in subjects with respiratory failure as severe as that induced in the original animal models. ${ }^{22}$ This hypothesis should perhaps be tested by reanalysing the unpublished study data to compare outcomes in the stratum of infants with most severe early disease.

In summary, accurate measures of respiratory disease severity have an important part to play in clinical practice and comparative studies. Static Crs appears to be a valuable index of the severity and prognosis of respiratory disease and - particularly in clinical management - might usefully complement more routine indices based on blood gases. Static Crs now merits wider evaluation.

We thank the nursing and medical staff in Ninewells Hospital neonatal unit for their support and Professor Richard Olver for his foresight and encouragement. This work was supported by grants from the Wellcome Trust, Scottish Office Home and Health Department, Action Rust and Stroke Association. A video of the and Stroke Association. A video of the static Crs technique is
avale from WOT-M at cost price.

1 Simbruner G. Inadvertent positive end-expiratory pressure in mechanically ventilated newborn infants: detection and effect on lung mechanics and gas exchange. $\mathcal{f}$ Pediatr 1986; 108: 589-95.

2 LeSouef PN, England SJ, Bryan AC. Passive respiratory mechanics in newborns and children. Am Rev Respir Dis 1983; 129: 552-6.

3 Avery ME, Tooley WH, Keller JB, et al. Is chronic lung disease preventable? A survey of eight centers. Pediatrics 1987; 79: 26-30.

4 Tarnow-Mordi WO, Ogston S, Wilkinson AR, et al. Prediction of death from initial disease severity in very low birth weight infants: a method for comparing the performance of neonatal units. BMF 1990; 300: 1611-4.

5 International Neonatal Network. The CRIB (clinical risk index for babies) score: a tool for assessing initial neonatal risk and comparing performance of neonatal intensive risk and comparing performance of

6 Simbruner G, Coradello H, Lubec G, Pollak A, Salzer H. Respiratory compliance of newborns after birth and its prognostic value for the course and outcome of respiratory disease. Respiration 1982; 43: 414-23.

7 Stenson BJ, Glover R, Parry G, Wilkie RA, Laing IA, Tarnow-Mordi WO. Static respiratory compliance in the newborn. III: Early changes following exogenous surfactant treatment. Arch Dis Child 1994; 70: F19-24.

8 Kirpalani H, Schmidt B, Gaston S, et al. Birthweight, early passive respiratory system mechanics, and ventilator requirements as predictors of outcome in premature infants with respiratory failure. Pediatr Pulmonol 1991; 10: infants

9 Migdal M, Dreizzen E, Praud JP, et al. Compliance of the total respiratory system in healthy preterm and full-term newborns. Pediatr Pulmonol 1987; 3: 214-8.

10 Haouzi P, Marchal F, Crance JP, Monin P, Vert P. Respiratory mechanics in spontaneously breathing term and preterm neonates. Biol Neonate 1991; 60: 350-60.

11 Thomson AH, Beardsmore CS, Silverman M. The total compliance of the respiratory system during the first year of life. Bulletin Europeén de Physiopathologie Respiratoire 1985; 21: 411-6.

12 Olinsky A, Bryan AC, Bryan MH. A simple method of measuring total respiratory system compliance in newborn infants. $S$ Afr Med F 1976; 50: 128

13 Wilkie RA, Bryan MH, Tarnow-Mordi WO. Static respiratory compliance in the newborn. II: Its potential for improving the selection of infants for early surfactant treatment. Arch Dis Child 1994; 70: F16-8.

14 Crowley P, Chalmers I, Kierse MJNC. The effects of corticosteroid administration before preterm delivery: an overview of the evidence. Br F Obstet Gynaecol 1990; 97: 11-25.

15 Yeh TF, Torre JA, Rastogi A, et al. Early postnatal dexamethasone therapy in premature infants with severe respiratory distress syndrome: a double-blind controlled study. $₹$ Pediatr 1990; 117: 273-82.

16 Kelly E, Bryan H, Possmayer F, Frndova H, Bryan C. Compliance of the respiratory system in newborn infants pre- and postsurfactant replacement therapy. Pediatr Pulmonal 1993; 15: 225-30.

17 Knaus WA, Draper EA, Wagner DP, Zimmerman JE. APACHE II: a severity of disease classification system. Crit Care Med 1985; 13: 818-29.

18 Pollack MM, Ruttmann UR, Getson PR, et al. Accurate prediction of the outcome of pediatric intensive care. $N$ prediction of the outcome of

19 Balakrishnan G, Aitchison T, Hallworth D, Morton NS. Prospective evaluation of the paediatric risk of mortality (PRISM) score. Arch Dis Child 1992; 67: 196-200.

20 Patterson CC, Halliday HL. Prediction of outcome shortly after delivery for the very low birthweight $(\leqslant 1500 \mathrm{~g})$ infant. Paediatr Perinat Epidemiol 1988; 2: 221-8.

21 HIFI Study Group. High-frequency oscillatory ventilation compared with conventional mechanical ventilation in the treatment of respiratory failure in preterm infants. $N \mathrm{Engl}$ f Med 1989; 320: 88-93.

22 Hamilton PP, Onayemi A, Smyth JA, et al. Comparison of conventional and high frequency ventilation: oxygenation and lung pathology. fournal of Applied Physiology: Respiratory, Environmental and Exercise Physiology 1983; 55: $131-8$.

23 Horbar JD, Onstad L, Wright E, et al. Predicting mortality risk for infants weighing 501 to 1500 grams at birth: a risk for infants weighing 501 to 1500 grams at birth: a report. Crit Care Med 1993; 21: 12-8. 